\title{
Who Provides Care to Medicare Beneficiaries and What Settings Do They Use?
}

George C. Xakellis, MD

Background: Concerns have been expressed that the physician workforce is unprepared for the explosion in the number of older persons in America. As a step toward informing these discussions, this article will describe how Medicare beneficiaries currently access physician services.

Methods: This study is a descriptive analysis of the physician services used by Medicare beneficiaries. The Medicare Beneficiary Survey (MCBS) data from 1998 are used for the analysis. The locations of service delivery were compared among family physicians, general internists, and geriatricians.

Results: The physician office was the most common site of service, comprising $49 \%$ of all provider claims. General internists $(20.1 \%$ of office claims) and family physicians $(\mathbf{1 8 . 6 \%}$ of office claims) were the most common providers. Family physicians spent the largest proportion of their time in the office (77\%), general internists were the most likely provider to see patients in the hospital (19\%), and geriatricians were the most likely to see patients in the nursing home (27\%) and at home (1.7\%).

Conclusions: Office-based care by general internists and family physicians constitute a major infrastructure element in the delivery of care to Medicare beneficiaries. The practices of geriatric medicine physicians are more heavily weighted toward the nursing home setting. (J Am Board Fam Pract 2004;17: 384-7.)

Concerns have been expressed that the physician workforce is unprepared for the explosion in the number of older persons in America. ${ }^{1,2}$ In this age wave, what role will the primary care physiciansgeneral internists and family physicians-play in caring for older persons. At the moment, only $1 \%$ of graduates from American medical schools choose geriatrics as a career, assuring a central role for both general internal medicine and family medicine in caring for older persons. ${ }^{3,4}$ In this environment, how will geriatric medicine physicians interface with the primary care disciplines of family medicine and internal medicine? ? $^{3-8}$

One necessary step toward answering these questions is to understand who is providing care to patients over age 65 right now. This article describes how Medicare beneficiaries currently access physician services. It will describe the beneficiaries'

Submitted, revised, 14 April 2004.

From the Department of Family \& Community Medicine, University of California, Davis. Address correspondence to George C. Xakellis, MD, Department of Family \& Community Medicine, University of California Davis Medical Center, 4860 Y Street, Room 2335, Sacramento, CA 95819 (e-mail: george.xakellis@ucdmc.ucdavis.edu). current use of physician services and locations at which they currently receive care.

\section{Methods}

This investigation was conducted using the Medicare Beneficiary Survey (MCBS) data from 1998. The Medicare Beneficiary Survey is a continuous survey of a representative sample of Medicare beneficiaries, including both aged and disabled enrollees. The sample includes 13,024 beneficiaries. The survey includes 2 components: 1) detailed interviews with participants 3 times yearly addressing their demographics, health status, and use of health care services; 2) insurance claims data from Medicare showing details of health care utilization and cost. Information from both components of the survey are then reconciled to calculate total health care utilization, cost and utilization for each category of use, and sources of payment for each person who participates in the survey.

The Medicare beneficiary survey has been conducted continuously from 1991. ${ }^{9}$ The survey sample is drawn from Medicare enrollment files. Because Medicare covers more than $95 \%$ of persons aged 65 or older, the survey is a good representation of this population. In particular, it is one of the 
few surveys that includes both community-dwelling and institutionalized persons. The survey gathers information from approximately 13,000 Medicare beneficiaries on demographic information, cost and use of services covered by Medicare, and use of services that are not covered (eg, prescription drugs, nursing home care, dental care). Information on use and expenditures is gathered in 3 in-person interviews per year with a recall period of 4 months. Memory aids are used to ensure completeness and accuracy. Expense data on Medicare-reimbursed services and mortality data are taken directly from Medicare records. Events reported by respondents are linked to claims. ${ }^{7}$

\section{Variables and Analysis}

The study is a descriptive analysis of provider and location of services obtained by Medicare beneficiaries. Variables were drawn from the itemized Medicare insurance claims data of medical provider services. Variables include provider specialty, frequency of service, and location of service. The provider claims data include only those claims submitted by a physician or other medical provider and do not include facility claims. Analyses were conducted at the service level. Physician specialty and location of service were determined based on the physician specialty code and location of service code listed on the submitted claim form.

\section{Results}

In 1998, 385,117 claims for provider services were filed for the 13,024 beneficiaries in the study database. The mean age of the 13,024 beneficiaries was $72 \pm 14$ years. Men comprised $43 \%$ of the sample and women comprised $57 \%$. Of these, 187,619 or $49 \%$ were for physician office visits (Table 1). General internal medicine was the most common physician specialty providing office-based service, accounting for $20.1 \%(37,763)$ of Medicare claims, followed by family physicians, accounting for $18.6 \%(34,812)$ of claims. The top 10 providers of office-based service are presented in Table 2.

The principal settings for the care of Medicare beneficiaries were compared among family physicians, general internists, and geriatric medicine physicians. The family physicians spent the largest proportion of time in the office setting, generating $77 \%$ of their Medicare claims from there. The general internist followed at $69 \%$, and then the
Table 1. Most Frequent Locations of Service by Physicians and Other Medical Providers for Medicare Beneficiaries-1998 (from Medicare Claims Data)*

\begin{tabular}{lrc}
\hline Location & $\begin{array}{r}\text { Frequency } \\
\text { of Claims }\end{array}$ & $\begin{array}{c}\text { Percentage } \\
\text { of Claims }\end{array}$ \\
\hline Office & 187,619 & 48.7 \\
Independent laboratory & 59,546 & 15.5 \\
Inpatient hospital & 59,092 & 15.3 \\
Outpatient hospital & 24,838 & 6.5 \\
Ambulance & 11,945 & 3.1 \\
Emergency room & 11,534 & 3.0 \\
Skilled nursing facility & 11,101 & 2.9 \\
Nursing facility & 8,129 & 2.1 \\
Home visits & 2,189 & 0.6 \\
Total & 385,117 & \\
\hline
\end{tabular}

* Representative sample of 13,024 Medicare beneficiaries.

geriatrician at $47 \%$. The general internists spent the largest proportion of time in inpatient hospital settings, generating $19 \%$ of their Medicare insurance claims from the hospital, followed by the geriatrician $(16 \%)$, and then by the family physician (9\%). Geriatricians spent the largest proportion of time in the nursing home, generating $27 \%$ of their Medicare insurance claims from nursing home care, followed by family physicians at $7 \%$, and then by general internists at $6 \%$. A breakdown of the locations at which these 3 physician groups generate their Medicare insurance claims is presented in Table 3.

Table 2. Top Ten Providers of Medical Care in the Office Setting (Based on Number of Submitted Medicare Claims) for Medicare Beneficiaries-1998*

\begin{tabular}{lcc}
\hline Type of provider & $\begin{array}{c}\text { Frequency } \\
\text { of Claims }\end{array}$ & $\begin{array}{c}\text { Percentage } \\
\text { of Claims }\end{array}$ \\
\hline General internal medicine & 37,763 & 20.1 \\
Family/general practice & 34,812 & 18.6 \\
Cardiology & 11,327 & 6.0 \\
Ophthalmology & 10,635 & 5.7 \\
Urology & 7,389 & 3.9 \\
Chiropractic & 7,286 & 3.9 \\
Orthopedic surgery & 6,906 & 3.7 \\
Podiatry & 6,644 & 3.5 \\
Hematology/oncology & 6,102 & 3.3 \\
Dermatology & 5,761 & 3.1 \\
\hline
\end{tabular}

* Geriatric medicine was the 38th most common health care provider in the office setting submitting $0.20 \%$ of Medicare claims. A representative sample of 13,024 Medicare beneficiaries; total number of office-based claims was 187,619 . 
Table 3. Distribution of Location of Service for Medicare Insurance Claims Submitted by Family Physicians, General Internal Medicine Physicians, and Geriatric Medicine Physicians-1998*

\begin{tabular}{lccc}
\hline Location & $\begin{array}{c}\text { Family Physician/ General Practitioner } \\
\text { (No of claims) }\end{array}$ & $\begin{array}{c}\text { General Internal Medicine } \\
\text { (No of claims) }\end{array}$ & $\begin{array}{c}\text { Geriatric Medicine } \\
\text { (No of claims) }\end{array}$ \\
\hline Office & $77 \%(34,812)$ & $69 \%(37,763)$ & $47 \%(377)$ \\
Inpatient hospital & $9 \%(4,117)$ & $19 \%(10,374)$ & $16 \%(131)$ \\
Outpatient hospital & $2.2 \%(1,012)$ & $3.4 \%(1,879)$ & $6.1 \%(49)$ \\
Nursing home & $7 \%(3,157)$ & $6.2 \%(3,406)$ & $27 \%(217)$ \\
Custodial board and care & $0.3 \%(125)$ & $0.2 \%(83)$ & $1.2 \%(10)$ \\
Emergency room & $3 \%(1,352)$ & $1.6 \%(872)$ & $0.4 \%(3)$ \\
Home & $0.6 \%(307)$ & $0.4 \%(205)$ & $1.7 \%(14)$ \\
Other & $0.9 \%(390)$ & $0.2 \%(353)$ & $0.6 \%(5)$ \\
Total & $100 \%(45,272)$ & $100 \%(54,935)$ & $100 \%(806)$ \\
\hline
\end{tabular}

* Representative sample of 13,024 Medicare beneficiaries.

\section{Discussion}

The purpose of this analysis was to describe which medical providers care for Medicare beneficiaries and which settings they use. The most common physician providers of care for Medicare beneficiaries are general internists and family physicians, who account for nearly $40 \%$ of all office visits billed to Medicare. These primary care physicians constitute a broadly distributed, decentralized base of care for Medicare beneficiaries. These physicians are major stakeholders in the process of care delivery to Medicare beneficiaries and will need to be deeply involved in the care delivery, particularly in the ambulatory setting, if older persons are to receive excellent health care.

Comparing the practice settings of geriatric medicine physicians, general internists, and family physicians identified some interesting patterns. Family physicians provide largely office-based services. The general internists have a somewhat smaller office-based practice, but tend to provide more hospital care than the family physicians. The geriatricians have a very different set of practice locations, spending less than $50 \%$ of their time in the office and almost $30 \%$ of their time in the nursing home. Home visits are relatively rare, constituting only $0.6 \%$ of provider claims. However, the rate of home visits by geriatric medicine physicians is over twice that of family physicians or general internists.

A distinguishing feature of geriatric medicine seems to be that nursing home care is a major component of their practice. Older persons in nursing homes tend to be frailer and to have more functional limitations than do community-dwelling seniors. It is not unreasonable to expect that geriatric physicians would expand this role by becoming more active in the care of similarly frail and functionally limited patients in ambulatory health care settings. In the area of home visits, geriatricians currently provide a higher proportion of their care in this setting than do family physicians or general internists. Although the numbers of home visits are small, which limits the ability to generalize, geriatricians seem to have a significant role to play in the delivery of care in this setting.

There are several limitations to this study. First, the specialty of the provider was self-reported and may not be accurate. There may be some family physicians or general internists who have geriatric certification but who reported their medical claims using the generalist ID codes. However, if this has occurred, it is unlikely to affect the results of the study, because the number of certified geriatricians is small compared with the total number of family physicians and general internists. This problem has not been a barrier in the past to comparison of practice style differences between physicians, even though all internal medicine subspecialists are also certified as general internists. Second, the numbers of home visits are small and the estimates of visit rates may not be stable.

\section{Summary}

Office-based care delivery by the general internists and family physicians is an important element in the delivery of care to Medicare beneficiaries. The practices of geriatric medicine physicians are currently more heavily weighted toward the nursing 
home setting and away from the office setting. Geriatricians may be the physician group to provide leadership in the future regarding the care of patients in the nursing home. Excellent care of the Medicare population will require continued involvement of family physicians, particularly in the office-based setting.

\section{References}

1. Mitka $M$. As Americans age, geriatricians go missing. JAMA 2002;287:1792-3.

2. Institute for Health and Aging, UCSF. Chronic care in America: a 21st century challenge [monograph on the Internet]. New Brunswick (NJ): Robert Wood Johnson Foundation; 1996 [cited 2003 Oct 17]. Available from: http://www.rwjf.org/publications/ publicationsPdfs/Chronic_Care_in_America.pdf.

3. Green LA, Fryer GE. General internists and family physicians: partners in geriatric medicine? Ann Intern Med 2003;139:594-6.

4. Hazzard WR. General internal medicine and geriatrics: collaboration to address the aging imperative can't wait. Ann Intern Med 2003;139:597-8.

5. American Geriatric Society [homepage on the In- ternet]. New York: American Geriatric Society; 2000 [updated 2000 May 1; cited 2003 Oct 14]. American Geriatric Society Health Care Systems Committee. American Geriatric Society (AGS) position statement: ambulatory geriatric clinical care and services; [about 3 screens]. Available from: http://www.americangeriatrics.org/products/ positionpapers/ambltry.shtml.

6. Hall WJ. Update in geriatrics. Ann Intern Med 1996;125:390-7.

7. American College of Physicians. Focus on subspecialization. Geriatrics: an interview with John R. Burton. IMpact [serial on the Internet]. 2000 Winter [cited 2003 Oct 14];6(2):[about 30 screens]. Available from: http://www.acponline.org/journals/impact/ winter2000.htm.

8. American Academy of Family Physicians [homepage on the Internet]. Leawood (KS): American Academy of Family Physicians; 2002 [updated 2002; cited 2003 Oct 14]. AAFP position statement on Certificate of Added Qualifications in Geriatrics (CAQ); [1 screen]. Available from: http://aafp.org/x6833.xml.

9. Lubitz J, Cai L, Kramarow E, Lentzner H. Health, life expectancy, and health care spending among the elderly. N Engl J Med 2003;349:1048-55. 